\title{
Evaluation of blood and bone marrow in selected canine vector-borne diseases
}

\author{
Anna S De Tommasi ${ }^{1}$, Domenico Otranto ${ }^{1}$, Tommaso Furlanello², Silvia Tasca², Cinzia Cantacessi ${ }^{3}$, \\ Edward B Breitschwerdt ${ }^{4}$, Dorothee Stanneck ${ }^{8}$, Filipe Dantas-Torres ${ }^{1,5}$, Gad Baneth ${ }^{6}$, Gioia Capelli ${ }^{7}$ \\ and Donato de Caprariis ${ }^{1 *}$
}

\begin{abstract}
Background: Bone marrow (BM) is a major hematopoietic organ that can harbour a variety of vector-borne pathogens; however, knowledge of BM pathological changes in dogs infected with vector-borne pathogens is limited. Thus, the aim of the present study was to assess the pathological changes in canine BM associated with natural infections by four vector-borne pathogens, as well as to determine the relationships between such changes and abnormalities of the peripheral blood.

Methods: Cytological disorders and pathological changes of the BM of 83 dogs naturally-infected with one or more of four vector-borne pathogens (i.e., Anaplasma platys, Leishmania infantum, Babesia vogeli and Hepatozoon canis) were evaluated and compared with the corresponding hematological findings.

Results: Dysgranulopoiesis and dysmegakaryocytopoiesis were the most frequently observed BM abnormalities in infected dogs. Erythroid suppression, and lymphocytic, monocytic and macrophage hyperplasia were also observed. Interestingly, associations between suppression and hyperplasia of specific cell lines in the marrow and corresponding changes in numbers of circulating peripheral blood cells were not observed.
\end{abstract}

Conclusions: Infections with one or more of the vector-borne pathogens examined in this study should be considered as differential diagnoses for secondary dysmyelopoiesis.

Keywords: Bone marrow, Cytology, Vector-borne pathogens, Dysplasia, Secondary dysmyelopoiesis

\section{Background}

The bone marrow (BM) is the major hematopoietic organ and a primary lymphoid tissue. In dogs, the BM can become infected with pathogens such as Leishmania infantum [1], Hepatozoon canis [2] and Anaplasma platys [3]; therefore, the $\mathrm{BM}$ is considered a sensitive tissue for the detection of these pathogens $[4,5]$. Since the above-mentioned pathogens are transmitted by arthropod vectors, they are commonly referred to as canine vector-borne diseases (CVBDs); CVBDs are widely distributed and highly prevalent throughout much of the world, including the southern Mediterranean region [6]. Furthermore, multiple canine vector-borne pathogens can simultaneously infect the same host, thereby causing co-infections, which may exacerbate disease severity

\footnotetext{
*Correspondence: donato.decaprariis@uniba.it

'Dipartimento di Medicina Veterinaria, Università degli Studi di Bari, Valenzano, Bari, Italy

Full list of author information is available at the end of the article
}

and alter clinical and pathological scenarios associated with single infections, thus complicating diagnosis, treatment and prognosis in co-infected dogs [7]. The presence of vectorborne pathogens in the BM may induce substantial alterations in erythrocyte, granulocyte, monocyte, lymphocyte and thrombocyte numbers and/or function. Despite the high prevalence of CVBDs [6], only a few studies have investigated BM alterations in dogs infected solely by $L$. infantum [8-10] or by Ehrlichia canis [11]. In these studies, BM alterations associated with infections by $L$. infantum included emperipolesis, megakaryocytes dysplasia and BM aplasia, whereas myelosuppression was induced by $E$. canis infection. However, thus far, knowledge of the BM alterations associated with infections by other CVBDs, including $H$. canis and B. vogeli, as well as with co-infections by multiple CVBD pathogens, is lacking. Therefore, the aim of the present study was to provide insights into the BM changes that occur in dogs naturally-infected by one or more of four 
vector-borne pathogens (i.e. A. platys, B. vogeli, $H$. canis and $L$. infantum) and to determine the relationships between such changes and corresponding peripheral blood abnormalities.

\section{Methods}

\section{Ethics statement}

Animals included in this study were handled according to the principles of Good Clinical Practice (VICH GL9 GCP, 2000). The study design and the experimental procedures were approved and authorized by the Italian Ministry of Health (authorization number DGSA nu. 0001997; 04/02/2011; cf. [12,13]).

\section{Animals}

Samples from 83 crossbred dogs, 47 males and 36 females, of different age (ranging from 3 months to 6 years of age), unequivocally diagnosed with one or more CVBD (based on serological, cytological and molecular assays performed on a variety of tissues) were selected from a collection of samples examined in previously published studies $[12,13]$. Dogs were selected based on the following criteria: (1) positivity to one or more vector-borne pathogens documented by cytology and molecular assays and (2) the suitability of blood and BM smears for subsequent cytological evaluation. BM smears with evidence of blood contamination (i.e. high number of mature neutrophils, numerous platelet aggregates and few marrow cells) were excluded from the study. The selected cases were divided into 4 groups according to the detected pathogen(s) (which included $A$. platys, B. vogeli, $H$. canis, and L. infantum, Table 1). No dog included in this study was E. canis seroreactive or PCR positive.

\section{Sample collection and laboratory procedures}

Blood samples were collected from the brachial or jugular vein of each dog and a complete blood count (CBC) was performed using an automatic cell counter (Abbott Cell-Dyn 3700, Laboratorio di Analisi Cliniche Veterinarie,

Table 1 Group classification of 83 dogs according to the infecting vector-borne pathogens

\begin{tabular}{lll}
\hline Group & CVBD & $\mathbf{N}^{\circ}$ of dogs \\
\hline Ap & Anaplasma platys & 10 \\
Hc & Hepatozoon canis & 33 \\
Li & Leishmania infantum & 13 \\
Co-i & Co-infections & H. canis - L. infantum \\
& H. canis - A. platys & 12 \\
& H. canis - Babesia vogeli & 10 \\
& A. platys - Babesia vogeli & 2 \\
& H. canis - A. platys - Babesia vogeli & 2 \\
Tot & & 83 \\
\hline
\end{tabular}

ACV Triggiano, Bari). Blood and buffy coat smears were prepared and stained with the MGG Quick Stain (Bio Optica Spa, Milan, Italy). Bone marrow aspirates were obtained under local anesthesia with lidocaine hydrochloride 2\%, (Lidocaina 20, Pfizer Olot, S.L.U., Spain; 1-2 ml SC). In particular, BM specimens were collected from the iliac crest using Rosenthal needles (16 or 18 gauges) and $10 \mathrm{ml}$ syringes and Giemsa-stained prior to microscopical examination to evaluate cytological changes.

\section{Cytological examination}

A 500-cell differential count was performed on BM smears; the myeloid to erythroid (M:E) ratio, myeloid maturation index (MMI), erythroid maturation index (EMI) were calculated. The maturation index was defined as the ratio between the number of proliferative phase cells and the number of maturation phase cells in the BM (typically 1:4 in mammals [14]); the MMI is defined as (myeloblasts + promyelocytes + myelocytes $) \div$ (metamyelocytes + bands + segmenters), while the EMI is defined as (rubriblasts + prorubricytes) $\div$ (rubricytes + metarubricytes) [15]. Reference ranges used in this study for each cell type and for the different ratios have been reported elsewhere [16,17].

The mean number of megakaryocytes was determined for each dog at low magnification (i.e. 10x); megakaryocytic hyperplasia was defined as $>3$ cells/low-power field [18]. The percentages of myeloid precursors, erythroid cells, and megakaryocytes with dysplastic features were determined. Dysplasia was defined as the occurrence of dysplastic features in over $10 \%$ of the counted cells $[19,20]$. The term 'depletion' of one or more BM cell lineages was used for dogs with peripheral cytopenia and $\mathrm{BM}$ within reference intervals or hypoplastic BM with a normal or reduced maturation index. Conversely, 'suppression' was used to indicate dogs with peripheral cytopenia, accompanied by BM hypoplasia and an increased maturation index [21].

\section{Statistical analysis}

The Fisher's exact test was used to evaluate the differences in the percentages of abnormalities among dogs with a single infection and between dogs with single infection and those with co-infection. Data were organized in several 2X2 contingency tables comparing, for each abnormality, dogs with a specific vector-borne disease with dogs with another vector-borne disease or a co-infection status, with the aim to reveal a significant higher prevalence of a given abnormality in the two groups. A publicly available online software was used (ㄷ)2014 GraphPad Software, Inc. at: http://www.graphpad.com/ quickcalcs/contingency2/). 
Table 2 Peripheral findings compared with BM pathologic changes (*)

\begin{tabular}{|c|c|c|c|c|c|c|c|c|c|c|c|}
\hline \multicolumn{7}{|l|}{ Blood } & \multicolumn{5}{|c|}{ Bone marrow } \\
\hline & & \multirow{3}{*}{$\begin{array}{l}\text { Ap } \\
\text { N/10 (\%) }\end{array}$} & \multirow{3}{*}{$\begin{array}{l}\mathrm{Hc} \\
\mathrm{N} / 33(\%)\end{array}$} & \multirow{3}{*}{$\begin{array}{l}\text { Li } \\
\mathrm{N} / 13(\%)\end{array}$} & \multirow{3}{*}{$\begin{array}{l}\text { Co-i } \\
\text { N/27 (\%) }\end{array}$} & \multirow{3}{*}{$\begin{array}{l}\text { Tot } \\
\text { N/83 (\%) }\end{array}$} & \multicolumn{5}{|c|}{ Erythroid suppression, myeloid and or megakaryocyte dysplasia } \\
\hline & & & & & & & $\overline{A p}$ & $\mathrm{Hc}$ & $\mathbf{L i}$ & Co-i & Tot \\
\hline & & & & & & & $\mathrm{N} / 10(\%)$ & N/33 (\%) & $\mathrm{N} / 13(\%)$ & $\mathrm{N} / 27(\%)$ & $\mathrm{N} / 83(\%)$ \\
\hline \multicolumn{2}{|l|}{ Normal CBC } & $0(0)$ & $1(3.0)$ & $3(23.1)$ & $1(3.7)$ & $5(6.0)$ & $0(0)$ & $1(3.0)$ & $3(23.1)^{a}$ & $0(0)^{\mathrm{a}}$ & $4(4.8)$ \\
\hline \multicolumn{2}{|c|}{ WBC increase in the differential count } & $2(20)$ & $14(42.4)$ & $1(7.8)$ & $6(22.2)$ & $23(27.7)$ & $2(20)$ & $12(36.4)^{b}$ & $0(0)^{b}$ & $4(14.8)$ & $18(21.7)$ \\
\hline \multirow[t]{2}{*}{ Cytopenia } & Anemia & $3(30)$ & $10(30.3)$ & $6(46.2)$ & $15(55.5)$ & $34(41.0)$ & $3(30)$ & $14(42.4)$ & $7(53.8)$ & $16(59.2)$ & $40(48.2)$ \\
\hline & Thrombocytopenia & $0(0)$ & $4(12.1)$ & $1(7.8)$ & $1(3.7)$ & $6(7.2)$ & & & & & \\
\hline \multirow[t]{2}{*}{ Bicytopenia } & Anemia/Thrombocytopenia & $1(10)$ & $4(12.1)$ & $0(0)$ & $3(11.1)$ & $8(9.6)$ & $2(20)$ & $4(12.1)$ & $2(15.4)$ & $4(14.8)$ & $12(14.4)$ \\
\hline & Anemia/Neutropenia & $1(10)$ & $0(0)$ & $2(15.4)$ & $1(3.7)$ & $4(4.8)$ & & & & & \\
\hline \multicolumn{2}{|l|}{ Pancytopenia } & $3(30)^{\mathrm{Cd}}$ & $0(0)^{C}$ & $0(0)$ & $0(0)^{d}$ & $3(3.6)$ & $3(30)^{\mathrm{Ef}}$ & $0(0)^{\mathrm{E}}$ & $0(0)$ & $0(0)^{f}$ & $3(3.6)$ \\
\hline & & & & & & Total & $10(100)$ & 30 (93.9) & $12(92.3)$ & $24(88.92)$ & 77 (92.8) \\
\hline
\end{tabular}

(*) significant differences are marked by equal letters (lowercase $=p<0.05$; uppercase $=p<0.01$ ). 


\section{Results}

CBC and BM findings are summarized in Tables 2, 3 and 4, respectively; the main dysplastic figures observed in the BM samples are reported in Table 4 and Figure 1. Most BM specimens did not display alterations in cellularity; moreover, the blast cell count was $<6 \%$ in all dogs, therefore the occurrence of acute myeloproliferative disorders, as a cytopathological differential diagnosis, was excluded. Out of 83 dogs included in this study, only 5 (6\%) had CBC counts within reference intervals, i.e. one $A$. platys and $H$. canis co-infected dog with no blood or $\mathrm{BM}$ abnormalities and one $H$. canis and three $L$. infantum infected dogs showing BM myeloid and/or megakaryocytic dysplasia, atypical mitosis and suppression of erythroid and/or myeloid lineage.

Eighteen of 23 non-cytopenic dogs (27.7\%) with white blood cells count abnormalities including leukocytosis $(n=12 / 23)$, neutrophilia $(n=6 / 23)$, eosinophilia $(n=20 / 23)$, lymphocytosis $(n=15 / 23)$ and monocytosis $(n=7 / 23)$ were characterized by dysplasia of the myeloid and/or megakaryocytic lineages. Four out of the 23 non-cytopenic dogs had myeloid 'suppression' and/or 'depletion' without evidence of dysplasia.

Single and multiple cytopenia (Table 2) were identified in 55 out of the 83 dogs enrolled in this study. Forty dogs $(48.2 \%)$ had a single peripheral cytopenia, of which 34 were anemic and 6 were thrombocytopenic. Three dogs had depletion of all BM lineages in association with severe lymphocytic hyperplasia; seven dogs displayed suppression of erythroid or myeloid lineage, whereas dysplastic changes in one or more BM lineages were detected in the remaining 30 dogs. Twelve out of 83 dogs had peripheral bi-cytopenia, in association with BM differential cell count abnormalities and typical features of dysplasia. Lastly, three pancytopenic A. platys-infected dogs, had BM changes consistent with both dysplastic features and abnormalities in the differential count.

\section{Discussion}

In this study, dysmyelopoiesis characterized by the presence of BM dysgranulopoiesis and dysmegakaryocytopoiesis was observed in dogs infected by $L$. infantum, $A$. platys and $H$. canis. Secondary dysmyelopoiesis, which is a non-clonal condition, has generally been associated with the administration of drugs such as estrogen and chloramphenicol, toxin exposure and other specific disease processes, including lead toxicity and iron deficiency [20].

Interestingly, in several instances, $\mathrm{BM}$ observations were not in accordance with the corresponding cell counts in peripheral blood, i.e. anemia $v s$ erythroid hypoplasia, normal WBC and PLT count $v s$ marrow lymphocytosis, monocytosis and megakaryocytic hyperplasia.

In addition, co-infection by two or more CVBD pathogens was associated with more severe BM disorders that were notably different from the abnormalities in dogs infected by a single pathogen.

Normocytic normochromic non-regenerative anemia (NNNA), which was observed in this study (data not shown), is a common finding in CVBDs, including leishmaniasis [1,22], hepatozonoosis [23,24] and, to a lesser extent, anaplasmosis [25]. Interestingly, our data indicates an association between the erythroid hypoplasia

Table 3 Main CBC findings in 83 dogs infected by different CVBD pathogens (*)

\begin{tabular}{|c|c|c|c|c|c|c|}
\hline \multicolumn{7}{|l|}{$\mathrm{CBC}$} \\
\hline & & Ap & $\mathrm{Hc}$ & $\mathrm{Li}$ & Co-i & Tot \\
\hline & & N/10 (\%) & N/33 (\%) & N/13 (\%) & N/27 (\%) & N/83 (\%) \\
\hline \multirow[t]{2}{*}{$\overline{\mathrm{RBC}}$} & Normal & $2(20)$ & 19 (57.6) & $5(38.5)$ & $8(29.6)$ & $34(41.0)$ \\
\hline & Anemia & $8(80)$ & $14(42.4)^{a}$ & $8(61.5)$ & $19(70.3)^{a}$ & $49(59.0)$ \\
\hline \multirow[t]{10}{*}{ WBC } & Normal & $2(20)$ & $4(12.1)$ & $6(46.1)$ & $7(25.9)$ & 19 (22.9) \\
\hline & Leukocytosis & $1(10)^{b}$ & $19(57.6)^{\mathrm{bCd}}$ & $1(7.7)^{C}$ & $7(25.9)^{d}$ & $28(33.7)$ \\
\hline & Leukopenia & $1(10)$ & $0(0)$ & $2(15.4)$ & $0(0)$ & $3(3.6)$ \\
\hline & Neutrophilia & $1(10)$ & $10(30.3)$ & $1(7.7)$ & $9(33.3)$ & $21(25.3)$ \\
\hline & Neutropenia & $4(40)^{\mathrm{Eg}}$ & $O(0)^{E}$ & $2(15.4)$ & $1(3.7)^{9}$ & $7(8.4)$ \\
\hline & Eosinophilia & $3(30)^{\mathrm{H}}$ & $26(78.8)^{\mathrm{HI}}$ & $3(23.0)^{\prime}$ & $14(51.8)$ & $46(55.4)$ \\
\hline & Monocytosis & $1(10)$ & $5(15.2)$ & $1(7.7)$ & $5(18.5)$ & $12(14.4)$ \\
\hline & Monocytopenia & $0(0)$ & $1(3.0)$ & $0(0)$ & $0(0)$ & $1(1.2)$ \\
\hline & Lymphocytosis & $2(20)^{\prime}$ & $21(75.8)^{\prime}$ & $5(38.5)$ & $13(48.1)$ & $41(49.4)$ \\
\hline & Lymphopenia & $1(10)$ & $0(0)$ & $1(7.7)$ & $1(3.7)$ & $3(3.6)$ \\
\hline \multirow[t]{2}{*}{ PLT } & Normal & $6(60)$ & $25(75.8)$ & $12(92.3)$ & $26(96.3)$ & 69 (83.1) \\
\hline & Reduced & $4(40)^{\mathrm{m}}$ & $8(24.2)$ & $1(7.7)$ & $1(3.7)^{\mathrm{m}}$ & $14(16.9)$ \\
\hline
\end{tabular}

${ }^{*}$ ) significant differences are marked by equal letters (lowercase $=p<0.05$; uppercase $=p<0.01$ ). 
Table 4 BM differential count and dysplastic changes in 83 dogs infected by different CVBD pathogens (*)

\begin{tabular}{|c|c|c|c|c|c|c|c|c|c|c|c|c|c|c|}
\hline \multicolumn{15}{|c|}{ Bone marrow } \\
\hline & & & \multicolumn{5}{|c|}{ Differential count } & & & \multicolumn{5}{|l|}{ Dysplasia } \\
\hline & & & \multirow{2}{*}{$\frac{A p}{N / 10(\%)}$} & \multirow{2}{*}{$\frac{\mathrm{Hc}}{\mathrm{N} / 33(\%)}$} & \multirow{2}{*}{$\frac{\mathrm{Li}}{\mathrm{N} / 13(\%)}$} & \multirow{2}{*}{$\frac{\text { Co-i }}{N / 27(\%)}$} & \multirow{2}{*}{$\frac{\text { Tot }}{\mathrm{N} / 83(\%)}$} & & & \multirow{2}{*}{$\frac{A p}{N / 10(\%)}$} & \multirow{2}{*}{$\frac{\mathrm{Hc}}{\mathrm{N} / 33(\%)}$} & \multirow{2}{*}{$\frac{\mathrm{Li}}{\mathrm{N} / 13(\%)}$} & \multirow{2}{*}{$\frac{\text { Co-i }}{N / 27(\%)}$} & \multirow{2}{*}{$\frac{\text { Tot }}{\text { N/83 (\%) }}$} \\
\hline \multicolumn{3}{|c|}{ BM lineage } & & & & & & Precursors & Abnormalities & & & & & \\
\hline \multirow[t]{6}{*}{ Erythroid } & \multicolumn{2}{|c|}{ Normal } & $6(60)$ & $20(60.6)$ & $3(23.0)$ & $14(51.8)$ & $43(51.8)$ & & & - & & & & \\
\hline & \multicolumn{2}{|c|}{ Hyperplasia } & $1(10)$ & $9(27.3)$ & $2(15.4)$ & $7(25.9)$ & $19(22.9)$ & Promyelocytes & Bilobated nuclei & - & - & $1(7.7)$ & $1(3.7)$ & $2(2.4)$ \\
\hline & \multicolumn{2}{|c|}{ Hypoplasia } & $3(30)$ & $4(12.1)^{\mathrm{A}}$ & $8(61.5)^{\mathrm{Ab}}$ & $6(22.2)^{b}$ & $21(25.3)$ & Metamyelocytes & Giants & $2(20)$ & $10(30.3)$ & $3(23.0)$ & $6(22.2)$ & $21(25.3)$ \\
\hline & \multirow[t]{3}{*}{ EMI } & Normal & $1(10)^{c}$ & $15(45.4)$ & $2(15.4)$ & $14(51.8)^{c}$ & $32(38.5)$ & & Basophilia cytoplasm & - & $4(12.1)$ & $4(30.8)$ & $4(14.8)$ & $12(14.4)$ \\
\hline & & Increased & $9(90)^{\mathrm{D}}$ & $18(54.5)$ & $9(69.2)$ & $10(37)^{\mathrm{D}}$ & $46(55.4)$ & & Vacuolized cytoplasm & - & - & $1(7.7)$ & $1(3.7)$ & $2(2.4)$ \\
\hline & & Reduced & - & - & $2(15.4)$ & $3(11.1)$ & $5(6)$ & Banda & Ring nuclei & - & $2(6)$ & $1(7.7)$ & - & $3(3.6)$ \\
\hline \multirow[t]{9}{*}{ Myeloid } & \multicolumn{2}{|c|}{ Normal } & $5(50)$ & $20(60.6)$ & $6(46.1)$ & $14(51.8)$ & $45(54.2)$ & & Basophilia cytoplasm & - & $1(3.0)$ & - & - & $1(1.2)$ \\
\hline & \multicolumn{2}{|c|}{ Hyperplasia } & $3(30)$ & $2(6)$ & $2(15.4)$ & $3(11.1)$ & $10(12)$ & Segmented & Dohle bodies & $3(30)$ & $6(18.1)$ & $2(15.4)$ & $4(14.8)$ & $15(18)$ \\
\hline & \multicolumn{2}{|c|}{ Hypoplasia } & $2(20)$ & $11(33.3)$ & $5(38.4)$ & $10(37)$ & $27(32.5)$ & & Hypersegmented & $6(60)$ & $11(33.3)$ & $7(53.8)$ & $10(37)$ & $34(41)$ \\
\hline & \multirow[t]{3}{*}{ MMl } & Normal & $2(20)$ & $16(48.5)$ & $8(61.5)$ & $12(44.4)$ & $38(45.8)$ & & Basophilia cytoplasm & $1(10)$ & - & $1(7.7)$ & - & $2(2.4)$ \\
\hline & & Increased & $3(30)$ & $6(18.1)$ & $4(30.8)$ & $8(29.6)$ & $21(25.3)$ & Monocytes/ Macrophages & Vacuolized cytoplasm & $3(30)^{\mathrm{O}}$ & $O(0)^{O p}$ & $1(7.7)$ & $5(18.5)^{p}$ & $9(10.8)$ \\
\hline & & Reduced & $5(50)$ & $11(33.3)$ & $1(7.7)$ & $7(25.9)$ & $24(28.9)$ & & Erythrophagocytosis & $2(20)$ & $4(12.1)$ & - & $5(18.5)$ & $11(13.2)$ \\
\hline & \multicolumn{2}{|c|}{$\begin{array}{l}\text { Lymphocytic } \\
\text { hyperplasia }\end{array}$} & $2(20)^{e}$ & $10(30.3)^{\mathrm{F}}$ & $10(76.9)^{\mathrm{eF}}$ & $15(55.5)$ & $37(44.6)$ & & Platelet phagocytosis & $2(20)$ & - & - & $1(3.7)$ & $3(3.6)$ \\
\hline & \multicolumn{2}{|c|}{$\begin{array}{l}\text { Plasma cells } \\
\text { hyperplasia }\end{array}$} & $2(20)^{9}$ & $15(45.4)$ & $9(69.2)^{9}$ & $13(48.1)$ & $39(47)$ & Megakaryocytes & Dwarfs & $4(40)$ & $8(24.2)$ & $2(15.4)$ & $4(14.8)$ & $18(21.7)$ \\
\hline & \multicolumn{2}{|c|}{$\begin{array}{l}\text { Monocytic } \\
\text { hyperplasia }\end{array}$} & $9(90)^{h}$ & $15(45.4)^{\mathrm{h}}$ & $8(61.5)$ & $17(63)$ & $49(59)$ & & Hyperlobulated nuclei & $3(30)$ & $4(12.1)$ & $2(15.4)$ & $2(7.4)$ & $11(13.2)$ \\
\hline \multirow{3}{*}{\multicolumn{2}{|c|}{ Megakaryocytes }} & Normal & $2(20)$ & $10(30.3)$ & $4(30.8)$ & $7(25.9)$ & $23(27.7)$ & & Hypolobulated nuclei & - & $6(18.1)$ & - & $1(3.7)$ & $7(8.4)$ \\
\hline & & Hyperplasia & $7(70)$ & $22(66.6)$ & $6(46.1)$ & $14(51.8)$ & $49(59.0)$ & & Disorganized nuclei & $7(70)^{\text {Qrs }}$ & $7(21.2)^{Q}$ & $3(23.0)^{r}$ & $6(22.2)^{5}$ & $23(27.7)$ \\
\hline & & Hypoplasia & $1(10)$ & $1(3.0)^{i}$ & $3(23.0)$ & $6(22.2)^{i}$ & $11(13.2)$ & & Fragmented cytoplasm & $6(60)^{\mathrm{TUv}}$ & $2(6)^{\top}$ & $0(0)^{\cup}$ & $4(14.8)^{v}$ & $12(14.4)$ \\
\hline \multirow{3}{*}{\multicolumn{2}{|c|}{ Mitosis }} & Normal & $6(60)^{1}$ & $17(51.5)^{\mathrm{m}}$ & $2(15.3)^{\operatorname{lm}}$ & $10(37)$ & $35(42.1)$ & & Inclusions & $2(20)$ & - & - & - & $2(2.4)$ \\
\hline & & Increased & $3(30)$ & $7(21.2)^{n}$ & $8(61.5)^{n}$ & $7(25.9)$ & $25(30.1)$ & & Emperipolesis & $5(50)^{z}$ & $4(12.1)^{\mathrm{zW}}$ & $2(15.4)$ & $12(44.4)^{\mathrm{W}}$ & $33(39.8)$ \\
\hline & & Reduced & $1(10)$ & $9(27.3)$ & $3(23.0)$ & $10(37)$ & $23(27.7)$ & Mitosis & Atypical & $0(0)^{x}$ & $2(6)^{Y}$ & $(61.5)^{X Y \beta}$ & $3(11.1)^{\beta}$ & $10(12)$ \\
\hline
\end{tabular}

$\left(^{*}\right)$ significant differences are marked by equal letters (lowercase $=p<0.05$; uppercase $=p<0.01$ ). 


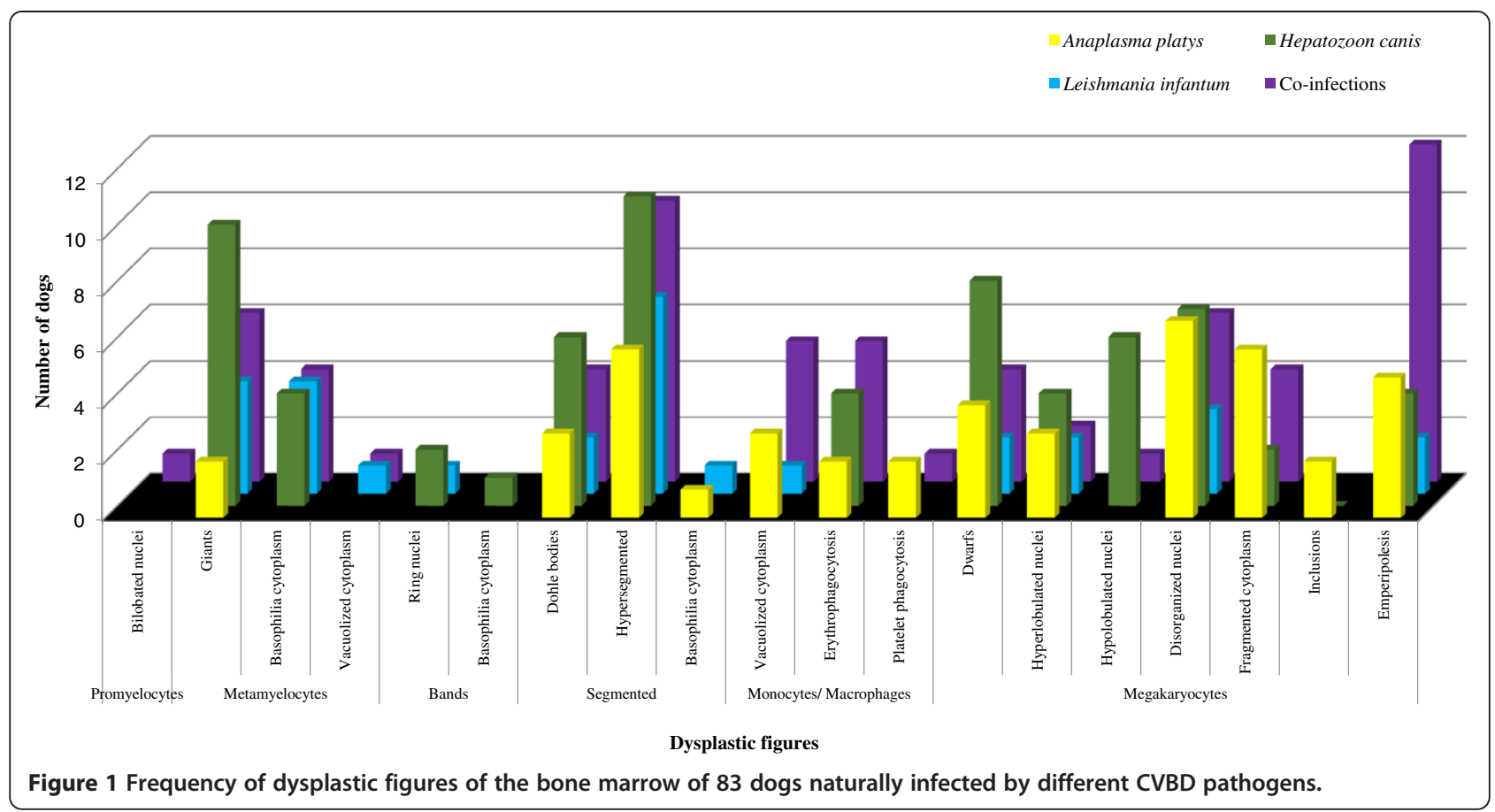

and L. infantum infection (group Li) when compared to co-infected dogs (Group Co-i) and H. canis-infected dogs. NNNA and erythroid hypoplasia with an increase in EMI was associated to small numbers of $L$. infantum parasites in BM samples, in contrast to a previous report in which non-regenerative anemia had been associated with large parasite numbers in the BM [9]. A nonregenerative anemia was also observed in dogs infected by $A$. platys and $H$. canis (group Ap and Hc, respectively) and was associated with an increased EMI, in spite of a reduced or even absent proliferation of erythroid precursors (i.e. rubriblasts and prorubrocytes) in the BM of infected animals. This may be due to the elicitation of a humoral and/or cell-mediated immune response directed against early erythroid precursors [19]. However, further studies are necessary in order to elucidate the relationship/s between infections by A. platys and H. canis infection and suppression of erythropoiesis.

Erythroid hyperplasia and mild dyserythropoiesis characterized by megaloblastic erythroid cells with multiple nuclei (Figure 2) were observed in two dogs $<8$ months of age. These morphologic abnormalities are most often seen in animals with myeloproliferative disorders, congenital dyserythropoiesis or following treatment with chemotherapeutic drugs [26]. It was unclear whether the changes observed in the BM of the two young animals were associated to an evolving myelodysplastic syndrome not yet manifested.

Eosinophilia was observed in $55.4 \%$ of the dogs and more frequently in $\mathrm{H}$. canis-infected dogs. Examination of $\mathrm{BM}$ smears from these dogs revealed myeloid cells within reference intervals or myeloid hypoplasia in association with an increased BM eosinophilic component (data not shown). Peripheral eosinophilia has already been linked to $H$. canis [24,27] and canine Bartonella infections [28,29]; however, it is important to note that this condition may also be caused by a number of diseases other than CVBDs [30], as well as by concomitant infections by gastrointestinal parasites which were not investigated in dogs included in this study. Leukocytosis was often observed in $H$. canis infected dogs (group Hc); interestingly, neutrophilia, which is usually associated with high rates of parasitemia [24], was not recorded in this study, possibly as a consequence of the small numbers of parasitized neutrophils (data not shown).

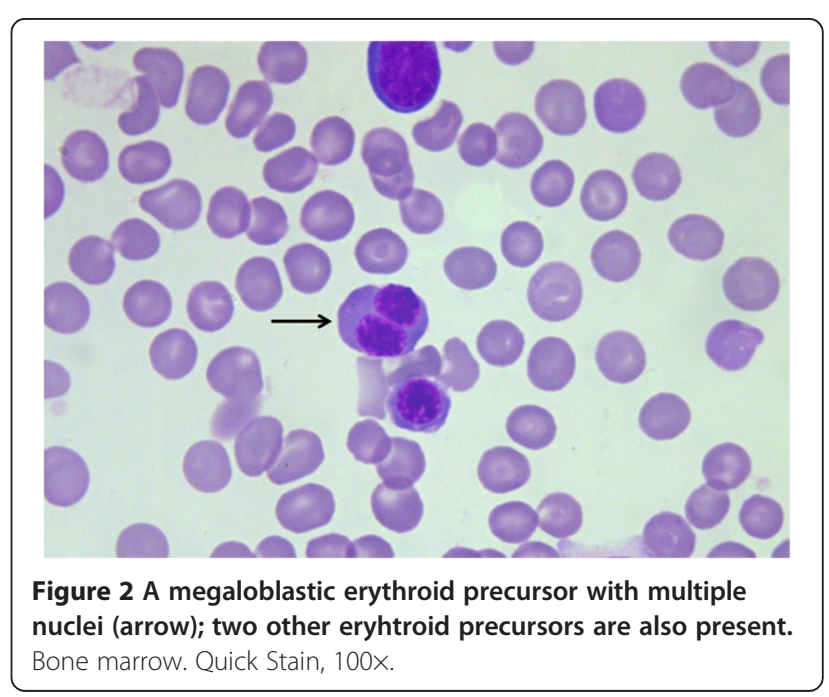




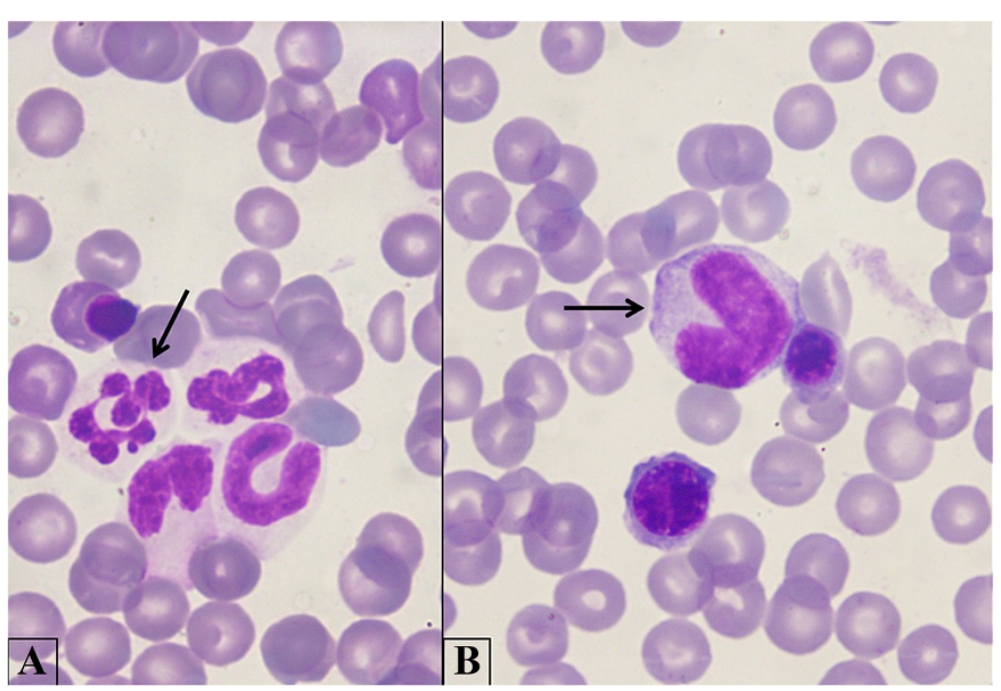

Figure 3 Myeloid dysplasia. A. A hypersegmented mature neutrophil (arrow); myeloid precursors in different maturation stages are also present. B. A giant metamyelocyte (arrow) with two erythroid precursors. Bone marrow. Quick Stain, 100x.

Myeloid hypoplasia, in association with normal peripheral WBC counts or with neutrophilia was observed in 11 (33.3\%) H. canis-infected dogs and in 10 (37\%) H. canis L. infantum co-infected dogs. This finding is not easily explained as granulocytic hypoplasia is generally associated with peripheral neutropenia. The BM of these animals was considered suppressed due to an absence of proliferation (MMI increased). It is possible that the mature neutrophilia in peripheral blood with simultaneous suppression of the myelocytic cell lines may be due to other factors such as mobilization and demargination of neutrophils due to stress and excitement [31].

Dysmorphic changes in neutrophilic granulocytes, which generally occurs in animals with inflammatory diseases and/or dysgranulopoiesis $[32,33]$ were observed, with varying prevalence (Table 4, Figures 3B, 1). Therefore, vectorborne pathogens, and in particular $H$. canis, should be considered among the secondary causes of dysgranulopoiesis in dogs. Indeed, morphological abnormalities were also observed in peripheral neutrophils (data not shown, Figure 3A) of dogs infected by H. canis (group Hc) and in H. canis co-infected dogs (Group Co-i).

Severe BM lymphocytosis, plasma cell hyperplasia and/ or monocytosis were frequently observed in dogs infected with $A$. platys, $L$. infantum and $H$. canis. This may be related to chronic antigenic stimulation as it has been shown for other CVBDs, such as canine monocytic ehrlichiosis [34]. Interestingly, these BM changes were not reflected in CBCs, since most dogs had peripheral blood lymphocytes and monocytes within reference intervals.

Hemophagocytic macrophages containing erythrocytes were observed in the $\mathrm{BM}$ of $A$. platys and $H$. canis infected dogs, whereas these cells were not detected in BM samples from L. infantum infected dogs, in contrast

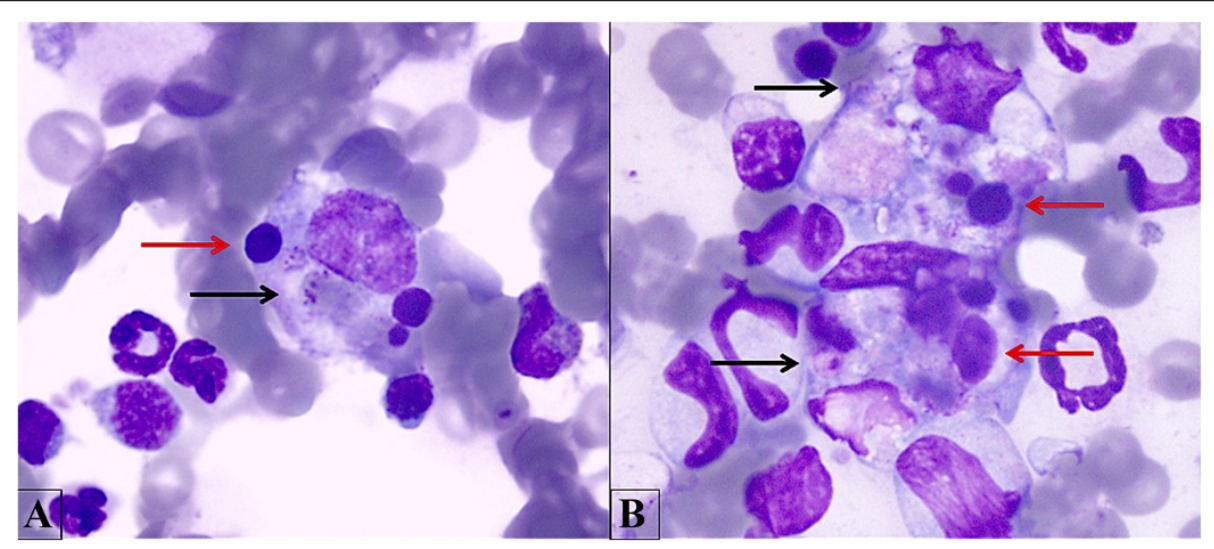

Figure 4 Platelets and erythrophagocytosis. A. A macrophage phagocyting erythroid precursors (red arrow), platelets (black arrow) and cellular debris. B. Two macrophages with the same features described in A. Bone marrow. Quick Stain, 100X. 


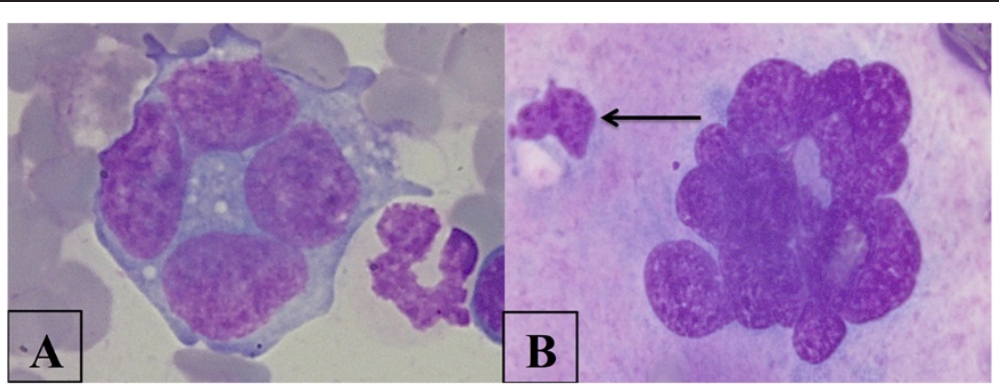

Figure 5 Megakaryocytic dysplasia. A. Megakaryocytic precursor with four divided nuclei. B. A megakaryocyte presenting morphologic abnormalities in nucleus shape and emperipolesis (arrow). Bone marrow. Quick Stain, 100X.

to a previous report [8]. Erythophagocytosis may be immune-mediated, due to antibody or possibly complement deposition on the surface of red cells, as it has been described for several vector-borne diseases [8]. It is also possible that infection-induced red cell abnormalities may alter membrane properties that result in reduced red cell lifespan and trigger phagocytosis [33]. Erythrophagocytosis may also occur as an "innocent bystander effect" whereby phagocytic macrophages remove red cells in the process of removing cellular debris, such as in the case of disseminated fungal infection [35], lymphocytic leukemia, myelomonocytic leukemia [36] and BM necrosis [37]. Erythrophagocytosis and platelet phagocytosis were observed in four A. platys infected dogs (Figure 4A,B), consistent with the immunemediated thrombocytopenia that this pathogen is known to induce $[38,39]$.

Megakaryocytic hyperplasia and dysplasia were the most frequent BM findings in this study. They were observed in all CVBD infection groups and they were especially frequent in $A$. platys infected dogs. Despite the presence of these abnormalities in the BM, numbers of platelets in peripheral blood were frequently normal. Features of megakaryocytic dysplasia included asynchronous maturation resulting in dwarf granular megakaryocytes, hyperlobulated, hypolobulated and/or disorganized nuclei (Figure 5A,B) and cytoplasmic abnormalities (tattered fringe and inclusions). We hypothesize an immunemediated cause for the megakaryocytic dysplasia observed, in accordance with previous reports of dogs infected by L. infantum [8].

Emperipolesis (Figure 5B), i.e. engulfing of various BM cells by megakaryocytes [40], was also frequently observed in this study. Emperipolesis increases in various disorders, including multiple myeloma, carcinoma, lymphoma [41], platelet disorders [42] and serious hemorrhage [43], however the pathophysiological importance of emperipolesisis is yet to be fully understood and its significance is uncertain $[44,45]$. Indeed, this event may be linked to the effects of interleukin-6 (IL-6), which alters the process of megakaryocyte maturation, thus altering thrombocytopoiesis
[45]. To our knowledge, prior to the present study, emperipolesis had only been described in dogs infected by L. infantum [8] and A. platys [39]; we describe, for the first time, emperipolesis in dogs infected or co-infected by $H$. canis. Lastly, atypical mitotic figures were noted infrequently in dogs infected or co-infected by $H$. canis and L. infantum (Figure 6), thus raising the question of whether selected CVBDs may indeed represent previously unrecognized causes of secondary dysmyelopoiesis.

\section{Conclusions}

This study provides information on the cytological disorders and pathological changes occurring in the BM of dogs naturally infected by a range of CVBD-causing pathogens. Dysgranulopoiesis and dysmegakaryocytopoiesis (i.e. emperipolesis) were typical BM alterations associated with $H$. canis infections. Megakaryocytic hyperplasia and dysplasia were observed in A. platys infected dogs, even in absence of thrombocytopenia at the time of testing, whilst infection with $L$. infantum was linked to BM erythroid suppression, infiltration of the BM with lymphocytes and plasma cells and the presence of atypical mitosis. Finally, more severe BM disorders were observed in dogs

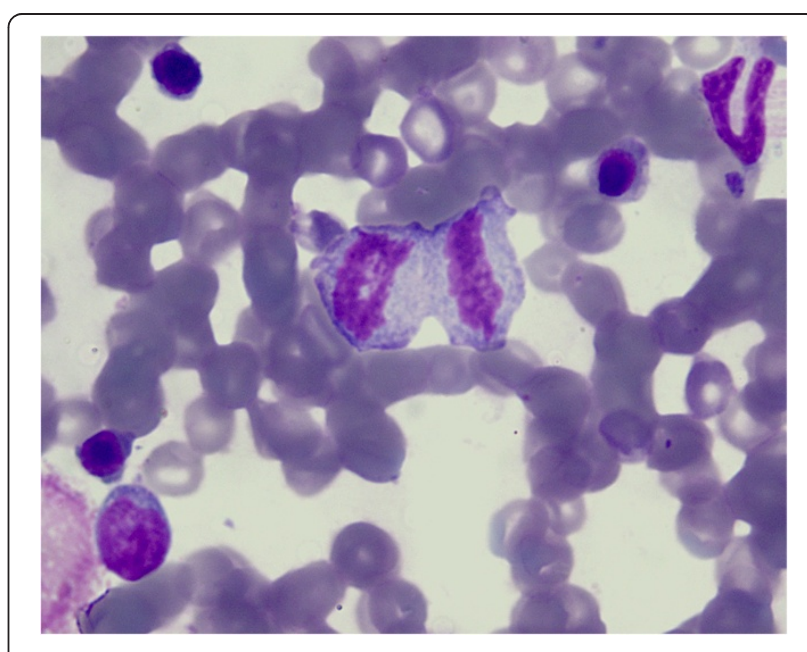

Figure 6 Atypical mitosis. Bone marrow. Quick Stain, 100x. 
co-infected by two or more CVBD pathogens than in dogs infected by a single agent. Based on our findings, infections by vector-borne pathogens should be considered as differential diagnoses for secondary myelodysplasia in dogs. Additional studies that further describe and explore mechanisms of BM changes induced by these agents and their relationship with observed changes in peripheral blood cell counts during the course of infection appear warranted.

\section{Abbreviations}

BM: Bone marrow; CVBD: Canine vector-borne disease; M:E: Myeloid to erythroid ratio; EMI: Erythroid maturation index; MMI: Myeloid maturation index; CBC: Complete blood count; PCR: Polymerase chain reaction; WBC: White blood cells; RBC: Red blood cells; PLT: Platelets;

NNNA: Normocytic normochromic non-regenerative anemia.

\section{Competing interests}

The authors declare that they have no competing interests.

\section{Authors' contributions}

ASDT, DdC and DO conceived the research, collected samples, contributed with data analysis and interpretation and wrote the first draft of the manuscript. ASDT and DdC performed cytological examination of both blood and BM samples. TF ST EBB and GB contributed with data analysis, interpretation and revision of the manuscript. CC and FDT contributed with revision of the manuscript. All authors read and approved the final version of the manuscript.

\section{Acknowledgements}

This research has been partially sponsored by Bayer Animal Health GmbH.

\section{Author details}

'Dipartimento di Medicina Veterinaria, Università degli Studi di Bari, Valenzano, Bari, Italy. 'Laboratorio d'Analisi Veterinarie "San Marco", Padova, Italy. ${ }^{3}$ Department of Veterinary Medicine, University of Cambridge, Cambridge, UK. ${ }^{4}$ Department of Clinical Sciences, Intracellular Pathogens Research Laboratory, Center for Comparative Medicine and Translational Research, College of Veterinary Medicine, North Carolina State University, 1060 William Moore Drive, Raleigh, NC 27607, USA. ${ }^{5}$ Department of Immunology, Aggeu Magalãhes Research Institute, Oswaldo Cruz Foundation, Recife, Pernambuco, Brazil. ${ }^{6}$ School of Veterinary Medicine, Hebrew University, Rehovot, Israel. ${ }^{~ I}$ Istituto Zooprofilattico Sperimentale delle Venezie, Laboratory of Parasitology, Legnaro, Italy. ${ }^{8}$ Bayer Animal Health $\mathrm{GmbH}$, Leverkusen, Germany.

Received: 23 April 2014 Accepted: 11 November 2014

Published online: 02 December 2014

\section{References}

1. FogliaManzillo V, Di Muccio T, Cappiello S, Scalone A, Paparcone R, Fiorentino E, Gizzarelli M, Gramiccia M, Gradoni L, Oliva G: Prospective study on the incidence and progression of clinical signs in naïve dogs naturally infected by Leishmania infantum. PLoS Negl Trop Dis 2013, 7:e2225.

2. Otranto D, Testini G, Dantas-Torres F, Latrofa MS, Diniz PP, de Caprariis D, Lia RP, Mencke N, Stanneck D, Capelli G, Breitschwerdt EB: Diagnosis of canine vector-borne diseases in young dogs: a longitudinal study. J Clin Microbiol 2010, 48:3316-24.

3. Eddlestone SM, Gaunt SD, Neer TM, Boudreaux CM, Gill A, Haschke E, Corstvet RE: PCR detection of Anaplasma platys in blood and tissue of dogs during acute phase of experimental infection. Exp Parasitol 2007, 115:205-10.

4. Solano-Gallego L, Miró G, Koutinas A, Cardoso L, Pennisi MG, Ferrer L, Bourdeau P, Oliva G, Baneth G, TheLeishVet Group: LeishVet guidelines for the practical management of canine leishmaniosis. Parasit Vectors 2011, 4:86.

5. Cardoso L, Cortes HC, Eyal O, Reis A, Lopes AP, Vila-Viçosa MJ, Rodrigues PA, Baneth G: Molecular and histopathological detection of Hepatozoon canis in red foxes (Vulpes vulpes) from Portugal. Parasit Vectors 2014, 7:113.
6. Otranto D, Dantas-Torres F: Canine and feline vector-borne diseases in Italy: current situation and perspectives. Parasit Vectors 2010, 3:2.

7. De Tommasi AS, Otranto D, Dantas-Torres F, Capelli G, Breitschwerdt EB, de Caprariis D: Are vector-borne pathogen co-infections complicating the clinical presentation in dogs? Parasit Vectors 2013, 15:97.

8. FogliaManzillo V, Restucci B, Pagano A, Gradoni L, Oliva G: Pathological changes in the bone marrow of dogs with leishmaniosis. Vet Rec 2006, 158:690-694.

9. Nicolato RC, de Abreu RT, Roatt BM, Aguiar-Soares RD, Reis LE, Carvalho M, Carneiro CM, Giunchetti RC, Bouillet LE, Lemos DS, Coura-Vital W, Reis AB: Clinical forms of canine visceral leishmaniasis in naturally Leishmania infantum-infected dogs and related myelogram and hemogram changes. PLoS One 2013, 8:e82947.

10. Momo C, Rocha NA, Moreira PR, Munari DP, Bomfim SR, Rozza DB, Vasconcelos Rde O: Morphological changes and parasite load of the adrenal from dogs with visceral leishmaniasis. Rev Bras Parasitol Vet 2014, 23:30-5.

11. Mylonakis ME, Day MJ, Siarkou V, Vernau W, Koutinas AF: Absence of myelofibrosis in dogs with myelosuppression induced by Ehrlichia canis infection. J Comp Pathol 2010, 142:328-31.

12. Dantas-Torres F, Capelli G, Giannelli A, Ramos RA, Lia RP, Cantacessi C, de Caprariis D, De Tommasi AS, Latrofa MS, Lacasella V, Tarallo VD, Di Paola G, Qurollo B, Breitschwerdt E, Stanneck D, Otranto D: Efficacy of an imidacloprid/ flumethrin collar against fleas, ticks and tick-borne pathogens in dogs. Parasit Vectors 2013, 6:245

13. Otranto D, Dantas-Torres F, de Caprariis D, Di Paola G, Tarallo VD, Latrofa MS, Lia RP, Annoscia G, Breitshwerdt EB, Cantacessi C, Capelli G, Stanneck D: Prevention of canine leishmaniosis in a hyper-endemic area using a combination of 10\% imidacloprid/4.5\% flumethrin. PLoS One 2013, 8:e56374.

14. Valli VE, McGrath JP, Chu I: Hematopoietic system. In Handbook of Toxicologic Pathology. 2nd edition. Edited by Haschek WM, Rousseaux CG, Wallig MA. San Diego, CA: Academic Press; 2002:647-79.

15. Weiss DJ, Lulich J: Myelodysplastic syndrome with sideroblastic differentiation in a dog. Vet Clin Pathol 1999, 28:59-63.

16. Melveger BA, Earl FL, Van Loon ED: Sternal bone marrow biopsy in the dog. Lab Anim Care 1969, 19:866-868.

17. Mischke R, Busse $L$ : References values for the bone aspirates in adult dogs. J Vet Med A 2002, 49:499-502.

18. Mischke R, Busse L, Bartels D, Glaser S, Kreienbrock L: Quantification of thrombopoietic activity in bone marrow aspirates of dogs. Vet J 2002, 164:269-74.

19. Weiss DJ, Aird B: Cytologic Evaluation of Primary and Secondary Myelodysplastic Syndromes in the Dog. Vet Clin Pathol 2001, 30:67-75.

20. Weiss DJ: Recognition and classification of dysmyelopoiesis in the dog: a review. J Vet Intern Med 2005, 19:147-154.

21. Raskin RE, Messick JB: Bone marrow cytologic and histologic biopsies: indications, technique, and evaluation. Vet Clin North Am Small Anim Pract 2012, 42:23-42.

22. Ciaramella P, Oliva G, Luna RD, Gradoni L, Ambrosio R, Cortese L, Scalone A, Persechino A: A retrospective clinical study of canine leishmaniasis in 150 dogs naturally infected by Leishmania infantum. Vet Rec 1997, 141:539-43.

23. Baneth G, Weigler B: Retrospective case-control study of hepatozoonosis in dogs in Israel. J Vet Intern Med 1997, 11:365-70.

24. Baneth G: Perspectives on canine and feline hepatozoonosis. Vet Parasitol 2011, 181:3-11.

25. Little SE: Ehrlichiosis and anaplasmosis in dogs and cats. Vet Clin North Am Small Anim Pract 2010, 40:1121-40.

26. Harvey JW: Veterinary Hematology: a Diagnostic Guide and Color Atlas. St. Louis Missouri, USA: Elsevier Saunders; 2012.

27. Otranto D, Dantas-Torres F, Weigl S, Latrofa MS, Stanneck D, Decaprariis D, Capelli G, Baneth G: Diagnosis of Hepatozoon canis in young dogs by cytology and PCR. Parasit Vectors 2011, 4:55

28. de Caprariis D, Dantas-Torres F, Capelli G, Mencke N, Stanneck D, Breitschwerdt EB, Otranto D: Evolution of clinical, haematological and biochemical findings in young dogs naturally infected by vector-borne pathogens. Vet Microbiol 2011, 149:206-212.

29. Breitschwerdt EB, Blann KR, Stebbins ME, Muñana KR, Davidson MG Jackson HA, Willard MD: Clinicopathological abnormalities and treatment response in 24 dogs seroreactive to Bartonella vinsonii (berkhoffii) antigens. J Am Anim Hosp Assoc 2004, 40:92-101.

30. Pollack MJ, Flanders JA, Johnson RC: Disseminated malignant mastocytoma in a dog. J Am Anim Hosp Assoc 1991, 27:435-440. 
31. Brown MR, Rogers KS: Neutropenia in dogs and cats: a retrospective study of 261 cases. J Am Anim Hosp Assoc 2001, 37:131-9.

32. Weiss D, Tvedten H: Erythrocyte disorders. In Small Animal clinical diagnosis by laboratory methods. 4th edition. Edited by Willard MD, Tvedten $\mathrm{H}$. Philadelphia: WB Saunders; 2004:38-62.

33. Jain NC: Essentials of Veterinary Hematology. Philadelphia, PA: Lea \& Febiger; 1993.

34. Harrus S, Waner T, Bark H, Jongejan F, Cornelissen AW: Recent advances in determining the pathogenesis of canine monocytic ehrlichiosis. J Clin Microbiol 1999, 37:2745-9.

35. Weiss DJ, Greig B, Aird B, Geor RJ: Inflammatory disorders of the bone marrow. Vet Clin Pathol 1992, 21:79-84.

36. Walton RM, Modiano JF, Thrall MA, Wheeler SL: Bone marrow cytologic features in 4 dogs and a cat with hemophagocytic syndrome. J Vet Intern Med 1996, 10:7-14.

37. Weiss DJ, Armstrong PJ, Reimann K: Bone marrow necrosis in the dog. J Am Vet Med Assoc 1985, 197:54-59.

38. Harvey JW, Simpson CF, Gaskin JM: Cyclic thrombocytopenia induced by a Rickettsia-like agent in dogs. J Infect Dis 1978, 137:182-188.

39. De Tommasi AS, Baneth G, Breitschwerdt EB, Dantas-Torres F, Otranto D, de Caprariis D: Anaplasma platys in bone marrow megakaryocytes of young dogs. J Clin Microb 2014, 52:2231-2234.

40. Thiele J, Krech R, Choritz H, Georgii A: Emperipolesis - a peculiar feature of megakaryocytes as evaluated in chronic myeloproliferative diseases by morphometry and ultrastructure. Virchows Arch B Cell Pathol 1984, 46:253-263

41. Lopes LF, Bacchi MM, Coelho KI, Filho AA, Bacchi CE: Emperipolesis in a case of B-cell lymphoma: a rare phenomenon outside of Rosai-Dorfman disease. Ann Diagn Pathol 2003, 7:310-313.

42. De Candia E, Larocca LM, Pecci A, Balduini CL: Marked emperipolesis and increased P-selectin expression on megakaryocytes in a novel case of gray platelet syndrome. J Thromb Haemostasis 2007, 5:193.

43. Dzieciol J, Debek W, Chyczewski L: Phenomenon of emperipolesis of bone marrow megakaryocytes in experimental hemorrhage shock in rats. Acta Haematol Pol 1994, 25:165-169.

44. Yener Y, Dikmenli M: The effects of acrylamide on the frequency of megakaryocytic emperipolesis and the mitotic activity of rat bone marrow cells. J Sci Food Agric 2011, 91:1810-1813.

45. Stahl CP, Zucker-Franklin D, Evatt BL, Winton EF: Effects of human interleukin- 6 on megakaryocyte development and thrombocytopoiesis in primates. Blood 1991, 78:1467-75.

doi:10.1186/s13071-014-0534-2

Cite this article as: De Tommasi et al:: Evaluation of blood and bone marrow in selected canine vector-borne diseases. Parasites \& Vectors 2014 7:534

\section{Submit your next manuscript to BioMed Central and take full advantage of:}

- Convenient online submission

- Thorough peer review

- No space constraints or color figure charges

- Immediate publication on acceptance

- Inclusion in PubMed, CAS, Scopus and Google Scholar

- Research which is freely available for redistribution 